\title{
A MÁQUINA DO MUNDO (RE)QUEBRADA: POEMAS REUNIDOS DE GERALDO CARNEIRO
}

\author{
Leonardo Vicente VIVALDO ${ }^{124}$
}

CARNEIRO, G. Poemas reunidos. Prefácio de Nelson Ascher. Rio de Janeiro: Nova Fronteira/Fundação Biblioteca Nacional, 2010. 464 p.

aqui, ao sul da máquina do mundo, onde só os cometas e os poetas perseveram na mesma trajetória.

(CARNEIRO, 2010, p.164, Poema "passatempo").

Geraldo Eduardo Carneiro nasceu "como muitos dos melhores cariocas, em Minas" (ASCHER, 2010, p.32) no ano de 1952, na cidade de Belo Horizonte. Mas, como a frase anterior já fez supor, o encontro com o Rio (Mar?) não tardou: em 1956 chegou "desembarcado sem gibão nem bacamarte/ na mui leal cidade de São Sebastião/ do Rio de Janeiro" (CARNEIRO, 2010, p.184) onde, marejado pelo surgimento da Bossa Nova, e pela efervescência econômica da construção de Brasília, viu sua casa ser frequentada tanto por um poeta e escritor como Paulo Mendes Campos; quanto por um músico e sambista como Jacob do Bandolim (em dois exemplos dentre, realmente, muitos outros de uma cultura dita "erudita" ou dita "popular"). E foi neste ambiente, no mínimo, heterogêneo (e que se refletirá em suas obras), que Geraldo Carneiro viu nascer o gosto pela produção artística (na qual, por conseguinte, o levaria a atuar nas mais diversas áreas). Mas apesar do interesse pela música popular (onde teve parcerias com Egberto Gismonti, Astor Piazzolla, Francis Hime, Wagner Tiso, etc), pelo cinema e pela televisão (com roteiros e produções), passando pela tradução (sobretudo de peças e poemas de William Shakespeare), parece que foi especialmente, ou justamente, na poesia que Geraldo Carneiro encontrou o verdadeiro "samba-enredo" para sua vida. Portanto, o livro Poemas Reunidos, lançado no ano passado pela editora Nova Fronteira (com apoio do Ministério da Cultura e da Fundação Biblioteca Nacional), veio não apenas para englobar os mais de 36 anos da poesia de Geraldo Carneiro - ou apenas

124 Mestrando do Programa de Pós-Graduação em Estudos Literários, Faculdade de Ciências e Letras, Universidade Estadual Paulista, UNESP, campus de Araraquara, CEP 14800-901, Araraquara, SP, Brasil leovivaldo@yahoo.com.br 
"Geraldinho", como é também conhecido (ou até mais conhecido) nos meios literário mas, por suposto, sublinhar o merecido destaque a este "Odisseu nos subúrbios da galáxia" (CARNEIRO, 2010, p.61) que há tanto tempo se deleita "no leito da poesia/ a deusa que me acolhe com constância" (CARNEIRO, 2010, p.97) por dentre uma poesia bem humorada, mas que nunca deixa de lado a reflexão: da própria poesia; como "corpo em si", estrutura; e da "alma" da poesia, como "voz(es)", tradição, ruptura.

Dessa forma, a dificuldade de se comentar Poemas Reunidos, de Geraldo Carneiro, não surge, apenas, por se tratar da reunião de toda a sua produção poética pois, obviamente, essa escapa das meras antinomias que um único livro, isolado, pode representar no todo da obra de um poeta. Na verdade, a dificuldade maior parece surgir mesmo é da própria composição particular que a poética de Geraldo Carneiro se vale: um caos de assonâncias e ressonâncias: tanto imagéticas, quanto sonoras e temáticas (sobre tudo intertextuais).

Mas, antes de adentrar especificamente a Sapucaí proto-poético de Geraldo Carneiro, ou para melhor adentrá-la, é preciso chamar atenção para a disposição estrutural de Poemas reunidos: do último para o primeiro livro - "Balada do Impostor" (2006) e "na busca do sete-estrelo" (1974). Sendo assim, Poemas reunidos fica configurado na seguinte ordem: "balada do impostor", 2006; "lira dos cinquent'anos", 2002; "por mares nunca dantes", 2000; “folias metafísicas”, 1995; “pandemônio", 1993; “piquenique em Xanadu”, 1988; “verão vagabundo", 1980; e "na busca do sete-estrelo", 1974.

Com tal escolha, Geraldo Carneiro, filho que foi da poesia marginal, parece não ter abandonando a postura "anti-tudo" e do melhor estilo "É proibido proibir" - que fomentou o início de sua produção. Entretanto, afora os resquícios de certa "Marginália" ${ }^{125}$, numa tentativa de se ir contra, às vezes muito menos pela postura sóciopolítica e mais pelo mero expediente de "ser do contra", a disposição apresentada, do último para o primeiro livro, parece tentar esconder por dentro da própria massa verbal da poesia as recorrências temático-estruturais que alicerçariam a poética carneriana como se, dessa maneira, aquilo que pela linha cronológica, e pelas pirações/fixações/coerências do poeta (e que com o tempo vão ficando mais nítidas, mais fortes), pudessem ir sendo dissolvidas (camufladas) por esse caminhar rumo ao

$125 \mathrm{O}$ neologismo é para enfatizar a mistura da postura marginal da poesia e a postura tropicalista da mú sica que parecem emergir da poesia de Carneiro. 
início da (sua) poesia: aquilo que ainda não estava "contaminado" pelas fixações que a labuta poética pode causar. É, em outras palavras, como se fosse possível um retorno ao "o tal do és pó e ao pós retornarás" (CARNEIRO, 2010, p.49) pelo caminho inverso, pois seria, aqui, não necessariamente, uma referência a morte, mas sim ao nascimento. O que era o homem antes do poeta? "Mero" homem. É, assim sendo, um retorno ao nascimento do poeta. Dessa forma o poeta vai se desconstruindo ao olhar o passado, pois é só no passado que ele pode se desfazer em nada, em não-poeta. No futuro, ainda que venha a morte (digo ainda, pois "se um dia for ceifado deste mundo/(como se vê, é um otimista irredutível)" (CARNEIRO, 2010, p.103)), a figura do poeta já está fixada no tempo: mesmo que morra ele é (poeta) - e sempre será (só em algum lugar do passado ele não foi). Portanto, é o passado que apaga o poeta e não o porvir - pois "um dia hei de ser múltiplo de mim/ do fim até o princípio" (CARNEIRO, 2010, p.50).

Um exemplo da importância desse movimento em direção ao passado (seja para "dissolver" ou "desvendar" algo) pode ser expresso em Poemas Reunidos pela figura do poeta por excelência: Orfeu, que é construído, desconstruído, perdido e encontrando por entre os livros de Carneiro, ganhando capítulos, poemas e se desdobrado em/por Odisseu, Eurídice, Prometeu (todos envoltos pelo "eu") e dos quais acaba se confundindo não apenas com o próprio poeta, mas com os outros poetas que perduram na poesia de Geraldo Carneiro: William Shakespeare (de quem encaixa, muito bem, em alguns versos, as sentenças do bardo inglês "pela eternidade e mais um dia" (CARNEIRO, 2010, p.28) e até a língua inglesa em alguns poemas), Dante, Poe, Mallarmé, numa lista que seria quase interminável em meio a alusões diretas e indiretas - como reforça o poema "autorretrato deprê" (que está no último livro, "balada do impostor", 2006 - portanto, primeiro de Poemas Reunidos):

não sei mais quase nada do que fui toda a memória vai virando escombros. hoje me reconheço mais nos outros poetas que freqüento desde sempre. a face deles segue imperturbada enquanto eu sofro as erosões do tempo. todo poeta nasce um pouco póstumo como volúpia de vencer a morte. a morte, esse ser vasto e corrosivo que nos vai corroendo desde dentro.

(CARNEIRO, 2010, p. 66). 
Fica claro a necessidade de reconhecer no outro a figura do eu que vai se perdendo através do tempo e novamente a importância desse mesmo tempo (de trás para frente) e que reforça o olhar para o passado (através da própria poesia ou das figuras e mitos: como é caso de Orfeu e das outras figuras já citadas). Além de Orfeu, merece destaque especialmente Camões (o poeta da língua) e de Bilac (poeta amado e maldito que em alguns poemas recebe o elogio e em outros o deboche mais franco. Aliás, Bilac, se confunde em Poemas Reunidos com Shakespeare - pois alguns poemas pretensamente psicografados de Bilac saem da "flor do lácio" e caem na língua do poeta inglês).

Já Luís Vaz de Camões, que também insurge em diversos momentos do livro (portando da obra) de Carneiro, vem para recobrar uma pretensa máquina do mundo, ainda que agora já (re)quebrada, e que tem seu apogeu em "para mares nunca dantes" (2000): poema "épico-burlesco" onde Camões, durante uma suposta travessia pelo Cabo das Tormentas (que só ocorreu num erro biográfico do filósofo francês Voltaire), por um “estranho estratagema astral" (CARNEIRO, 2010, p.184), acaba desembarcando no Rio de Janeiro de hoje - com seus "office-tubinamboys", executivos, prostitutas, travestis e pais de santos. Entretanto, ainda que a viagem imaginária de Camões sirva de pretexto para a viagem poética de Carneiro, por trás das peripécias de Luís Vaz, pela "terra das vergonhas saradinhas" (CARNEIRO, 2010, p.184), conforme expressão do próprio Pero Vaz de Caminha, é a linguagem que parece coatuar como protagonista de "por mares nunca dantes", pois ali faz desvelar no mar algo que já se fazia presente por toda a poesia de Carneiro, como denuncia o poema "a voz do mar":

\footnotetext{
na nave língua em que me navego só me navego eu nave sendo língua ou me navego em língua, nave e ave. eu sol me esplendo sendo sonhador eu esplendor espelho especiaria eu navegante, o anti-navegador de Moçambiques, Goas, Calecutes, eu que dobrei o Cabo da Esperança desinventei o Cabo das Tormentas, eu desde sempre agora nunca mais cultivo a miração das minhas ilhas. eu que inventei o vento e a Taprobana, a ilha que só existe na ilusão, a que não há, talvez Ceilão, sei lá, só sei que fui e nunca mais voltei me derramei e me mudei em mar; só sei que me morri de tanto amar
} 
Portanto, as figuras de poetas e mitos vão se atracando na poesia de Carneiro, através da "nave língua" que podem içar velas e (re)tornarem as mais improváveis praias - como se essa língua e essas figuras se fizessem do movimento das ondas que parecem tudo compor e para onde as palavras acabam contendo umas as outras e não apenas "pelo mero prazer das ressonâncias" (CARNEIRO, 2010, p.145), mas como se fosse possível "a fala aflora à flor da boca" (CARNEIRO, 2010, p.234) num movimento incontrolável - como as mares. Deste modo, o fazer poético de Carneiro sugere uma “procura da palavra mágica/ a contrassenha do apocalipse” (CARNEIRO, 2010, p. 298) tal a força da palavra, da poesia, que é o contrário da destruição (apocalipse) - enfim, epifania do verbo.

De modo geral, na poesia de Geraldo Carneiro, notamos a consciência da forma - herança das vanguardas (sobretudo do Concretismo) - mas nota-se coexistir de maneira (relativamente) harmoniosa. Em princípio, a marginalidade das últimas produções de Poemas Reunidos (cronologicamente as primeiras do poeta) acabam dando vazão a uma maior consciência já anunciada, criando uma poética onde desfila, com a mesma "ginga", a mitologia e o carnaval e em, no mais das vezes, "pelo formol formal dos decassílabos" (CARNEIRO, 2010, p. 105). Nesse jogo de (aparente) contradição, a tradição é constantemente revisitada por Geraldo Carneiro minstituindo, assim, uma poética rica de detalhes e que, de toda maneira, pela citação de outros autores (e mesmo pela auto-citação), (re)cria um universo coerente e com tantas ressonâncias dentro de si mesmo que quase escapa para o caos, mas que reverbera harmônico: tal quais as baterias "nota 10" que enchem a avenida. 